\title{
Dossiê
}

\section{Estudos Sociais da Ciência}

\author{
Introdução ${ }^{1}$
}

\author{
ANTONIO AUGUSTO PASSOS VIDEIRA | UERJ, CNPq \\ CRISTINA DE AMORIM MACHADO | UEM
}

0 presente dossiê reúne artigos especialmente elaborados e redigidos em torno da questão - certamente necessária para alguns deles - relativa às interações entre science studies e filosofia da ciência, de um lado, e história da ciência de outro. Não nos parece incorreto afirmar que essas interações já foram mais fortes e isto num passado nem tão longínquo assim. Ainda na década de 1990, falava-se, em não poucos lugares, da necessidade de estreitarem os laços entre as diferentes disciplinas das chamadas ciências humanas de modo a que se produzisse uma imagem mais adequada, fiel ou mesmo verdadeira da ciência. Em favor dessa postura positiva, podemos mencionar os muitos resultados obidos por historiadores, sociólogos e filósofos, como Bruno Latour, Lorraine Daston, lan Hacking, Peter Galison, Dominique Pestre, Mario Biagioli, entre muitos e muitos outros. Na virada do século XX para o XXI, contudo, esses discursos se enfraqueceram a ponto de serem, nos dias que correm, minoritários, praticamente inaudíveis.

Contrariamente ao que apregoa o "espírito" dos science studies, ocorreu um forte movimento de disciplinarização naquelas ciências que anteriormente se dedicavam à defesa de uma ciência organizada em torno de uma prática local. Essa disciplinarização levou, como já afirmado, a uma diminuição nos diálogos interdisciplinares. Esse quadro parecenos, por várias razões, inadequado e mesmo perigoso. A autossuficiência disciplinar é um mal a ser sempre evitado, principalmente quando ele pode descambar para atitudes regulatórias e, consequentemente, favoráveis à endogenia e ao insulamento.

Preocupados com essa disciplinarização, ou ainda, excessiva especialização, resolvemos organizar um dossiê que defendesse, por meio de argumentos e exemplos concretos, a posição favorável ao diálogo. A escolha pela Revista Brasileira de História da Ciência pareceu-nos óbvia, tendo em vista a sua natureza, bem como a prática da sociedade por ela responsável: a Sociedade Brasileira de História da Ciência. Tanto uma quanto outra, e desde os seus primórdios, se constituíram em torno de práticas interdisciplinares, atraindo e acolhendo profissionais e estudantes das mais diferentes áreas do conhecimento.

1 Agradecemos a acolhida das editoras da Revista Brasileira de História da Ciência. 
Os artigos aqui reunidos possuem, quase todos, uma "queda" para a filosofia. Em parte, isso se explica pelo fato de os seus autores atuarem principalmente nessa área. Mas não só por isso. Também a filosofia sofre de um certo isolamento. A sua presença numa revista de história da ciência, esperamos nós, deverá se prestar para a recuperação da atenção e do interesse dos filósofos por essa área do conhecimento, tal como já foi o caso. Traço comum a todos esses artigos encontra-se na sua caracterização da filosofia da ciência como sendo um domínio necessitado e desejoso de interação, seja com a ciência, seja com as suas parceiras das humanidades.

0 artigo de abertura, escrito por James McGuire e Barbara Tuchanska, defende uma concepção de filosofia da ciência elaborada em torno da noção de entendimento contextual, a qual possibilitaria o recurso à forma de vida como elemento essencial para a compreensão da prática científica.

No segundo trabalho, Kenneth R. Camargo Jr. preocupa-se em analisar e descrever, tomando Kuhn como ponto de partida mas também fazendo uso de outras perspectivas teóricas, as práticas médicas, de modo a poder elaborar um modelo epistemológico adequado para o saber biomédico.

Em seguida, André Luís de Oliveira Mendonça critica, mostrando a sua inconsistência e donde o seu malogro, a tentativa de Joseph Rouse de deslegitimizar o projeto de legitimação da ciência. Ainda que Rouse tenha fracassado no seu objetivo maior, Mendonça acredita que suas ideias podem ser inspiradoras para todos aqueles que recusam divisões de todo e qualquer tipo, renovando, inclusive, a nova história da ciência presente, mas não apenas, no interior dos science studies.

Também recorrendo a Kuhn e a Rouse, Leticia Minhot discute os fundamentos da psicanálise freudiana tal como 0 próprio Freud os apresentou e empregou. Uma das suas conclusões aponta para a presença das matrizes disciplinares kuhnianas na obra de Freud.

0 quinto artigo, de Cristina de Amorim Machado e Bruno Cava, assume uma identidade que se poderia classificar como prática, na medida em que pretende, recorrendo aos science studies, compreender a prática científica feita no Brasil. 0 recurso aos science studies se dá aqui de forma completa, ou seja, recuperando uma tendência presente entre os "pais fundadores" desse campo de pesquisa de que a compreensão da ciência deveria levar à sua avaliação crítica, perpetrada com o fim de aperfeiçoá-la e melhorá-la.

Finalmente, o último artigo descreve e discute "as ligações dissimuladas de caráter militar das expedições científicas organizadas pelo National Bureau of Standards e pela National Geographic Society para a observação do eclipse total do Sol de 20 de maio de 1947, em Bocaiuva (MG)." Em que pese o interesse pelo fenômeno astronômico, Heráclio Tavares afirma, baseando-se em documentos que encontrou em arquivos norte-americanos, que entre os autênticos objetivos dessas expedições científicas os militares eram os que de fato contavam, especificamente aqueles voltados para 0 aperfeiçoamento dos sistemas de controle de mísseis intercontinentais.

Antes de passarmos a palavra aos autores dos artigos aqui coligidos, permitimo-nos algumas observações históricas sobre os science studies. Estas palavras podem ser lidas como uma espécie de abertura ao dossiê.

A ciência é um dos muitos saberes produzidos pela humanidade, certamente o de maior prestígio na atualidade. Há controvérsias sobre uma série de questões, mas ninguém constestaria que ela é um produto coletivo, feito por pessoas reunidas em instituições científicas e que compartilham instrumentos, teorias, visões de mundo, metodologias, valores etc. Tendo em vista esse caráter social da ciência, uma das premissas dos science studies é justamente a prática científica.

Os science studies são estudos nos quais é possível perceber o predomínio de abordagens históricas, sociológicas e filosóficas sobre as ciências naturais, sobre as ciências da saúde e sobre as inúmeras "aplicações" tecnológicas "extraídas" destas mesmas ciências. As ciências são tomadas como práticas locais, condicionadas social, material e culturalmente, que também atuam no contexto social em que se encontram. As relações entre ciência e sociedade 
ganham uma dimensão de destaque. Os autores dos science studies pretendem sensibilizar os cientistas para as questões sociais e também aproximar a ciência do grande público, o chamado público leigo. Vejamos, de modo breve e superficial, como surgem os science studies no contexto da Filosofia da Ciência do século passado e no seu encontro com a História e a Sociologia da Ciência.

Grosso modo, a Filosofia da Ciência é inaugurada como disciplina acadêmica na Viena do fim da década de 1920. A principal preocupação, tanto dos positivistas lógicos do Círculo de Viena quanto de Karl Popper, era com o método científico, concebido como universal, atemporal e principal traço distintivo da ciência. Apesar de discordarem quanto ao método - indutivo para os primeiros e hipotético-dedutivo para o segundo -, podemos tomá-los como representantes de um modelo normativo-demarcacionista de Filosofia da Ciência.

Após algumas décadas de grande influência - principalmente em países anglo-saxões - a partir dos anos 1960, a insuficiência disciplinar desse modelo foi detectada por autores como N. R. Hanson, Thomas Kuhn, Imre Lakatos e Paul Feyerabend. Eles criticavam o positivismo lógico e o racionalismo crítico, que propunham critérios de demarcação muito estritos e puramente metodológicos entre os domínios científico e não-científico. Em resposta a esses modelos, Lakatos e Kuhn propuseram modelos orientados historicamente, e Feyerabend rompeu completamente com a ideia de critérios absolutos de cientificidade e de que o conhecimento científico era superior ou melhor que outros sistemas de pensamento. Pluralista teórico, metodológico e epistemológico, aproximou-se do relativismo, autodenominou-se anarquista e dadaísta, e preocupou-se com a relação entre ciência e democracia.

Ao longo das duas décadas seguintes, as relações entre filosofia, história e sociologia da ciência foram se modificando, às vezes com aproximações teóricas e institucionais, às vezes com afastamentos. A partir dos anos 1980, num movimento interdisciplinar, alguns autores começam a falar em science studies, agregando as três disciplinas, embora pendendo às vezes mais para um lado ou para outro. Há algumas características comuns que podemos identificar - foco na prática científica, concepção de ciência desunificada, relação entre ciência e sociedade etc. -, bem como questionamentos que se podem fazer - em que se diferenciam de outras correntes? - como veremos em alguma medida nos artigos que se seguem.

Um dado importante para definir um novo campo de pesquisa, além da formação de grupos de pesquisa, programas de pós-graduação e realização de eventos, é o material bibliográfico. Os science studies já contam com uma produção considerável, com textos e autores que podemos considerar clássicos. Muitos deles já foram citados e ainda aparecerão nas páginas que se seguem. 